\title{
THE PRODUCTION OF PAIN IN EXERCISING SKELETAL MUSCLE DURING INDUCED ANOXEMIA ${ }^{\mathbf{1 , 2}}$
}

\author{
By MILTON KISSIN \\ (From the Heart Station and the Cardiovascular Laboratory, Department of \\ Physiology, Michael Reese Hospital, Chicago)
}

(Received for publication September 1, 1933)

It is almost universally accepted that ischemia of the heart is the cause of pain in angina pectoris $(1,2,3)$. This idea was advanced many years ago by Jenner (4), Parry (5), and Burns (6). Experiments with animals by Pearcy, Priest, and Van Allen (7), Sutton and King (8), and Sutton and Lueth (9) seem to support this view.

Zak (10) observed that when the forearm muscles are rendered ischemic by a tourniquet, repeated contractions produce pain in the contracting muscles. He noted that the pain is like that of intermittent claudication and attributed the pain of intermittent claudication to arterial spasm.

MacWilliam and Webster (11) made further experiments on muscle pain. They noted: "that the pain ... arises from the exercise of ... muscle tissue ... in the presence of an acute lack of blood supply, involving urgent want of oxygen (anoxaemia) and its consequences, with excessive accumulation of metabolic products, acids, and other bodies." They felt that the symptoms of intermittent claudication had the same mechanism of production and were of the same nature as the symptoms demonstrable in the ischemic limb of the healthy subject. They also pointed out that the pain of angina pectoris probably arose similarly" that processes of the same nature, with a similar production of pain of varying grades of severity, up to the agonizing suffering of fully developed angina, occur in cardiac muscle compelled to work with a blood supply that is inadequate-absolutely or relatively to the amount of work which the heart has to perform."

The comprehensive study made by Lewis, Pickering and Rothschild (12) brought out new facts which disprove some of the older theories and demonstrate the probable nature of the cause of continuous muscular pain. Their experiments demonstrate that " pain characterizing intermittent claudication can be reproduced in a normal limb by exercising it after stopping

1 Aided by a grant from the Herbert L. Celler Fellowship Foundation, New York, and the Frederick K. Babson Fund of the Michael Reese Hospital, Chicago.

${ }^{2}$ A preliminary report appeared in the Proc. Soc. Exper. Biol. and Med., 1932, 30, 114. 
its blood supply." They showed clearly that the pain is not due to arterial spasm. They demonstrated that lack of oxygen is not the direct cause of the pain but considered that it is quite probably an indirect cause. The pain is attributed to " a chemical or physico-chemical stimulus developed in the muscle mass during its exercise." This stimulus is termed a pain factor or factor $P$. They believe it is the accumulation of this $\mathrm{P}$ factor that causes the pain of intermittent claudication and of angina pectoris.

Reid (13) working in the laboratory of MacWilliam, made further observations on muscle pain. He states, “The abrupt disappearance of the pain (within a few seconds after readmission of blood) points to a chemical cause, and, more particularly, to the influence of unoxidized products of muscular activity on the sensory nerve-endings."

Keefer and Resnik (14) on theoretical grounds concluded that the anginal pain occurring in ischemia of the myocardium is to be attributed to the associated anoxemia. Recently, Rothschild and Kissin (15) and Dietrich and Schwiegk (16) were able to precipitate attacks of precordial pain by inducing a generalized anoxemia in patients presenting a history of attacks of angina pectoris.

The present investigation was designed to determine whether anoxemia without ischemia would lead to pain in healthy exercising skeletal muscles.

\section{OBSERVATIONS}

Eight young normal subjects having no evidence of peripheral vascular disease were studied. A progressive generalized anoxemia was induced by rebreathing from a 20 liter tank connected in series with an 8 liter spirometer; the accumulation of carbon dioxide was prevented by passing the expired air over soda-lime. A variable period ( 0 to 5 minutes) after starting rebreathing the subject began to squeeze an ergograph (Lewis (12)) at a definite rate set by a metronome (12 to 60 times per minute). The period of anoxemia was ended when the subject indicated any discomfort or when he became extremely cyanotic. The exercise, however, was continued at the set rate for a further period of several minutes. At the end of this experiment the subject described the sensations experienced. In six of the eight subjects psychic bias was precluded because the subjects were ignorant of the nature of the experiment. At the end of the anoxemic period a sample of expired air was drawn from a tap close to the subject, and the oxygen and carbon dioxide content determined by analysis with a Haldane apparatus.

As a control, each subject while breathing room air repeated his exercise at the same rate and as nearly as possible in the same position as in the anoxemia experiments. The sensations experienced by the subject during the control period were compared with the sensations during anoxemia.

The results are summarized in Table $I$. It will be noted that pain appeared in the exercising muscles in all eight subjects of the anoxemia ex- 
TABLE I

Effect of generalized anoxemia on the production of pain in exercising muscle

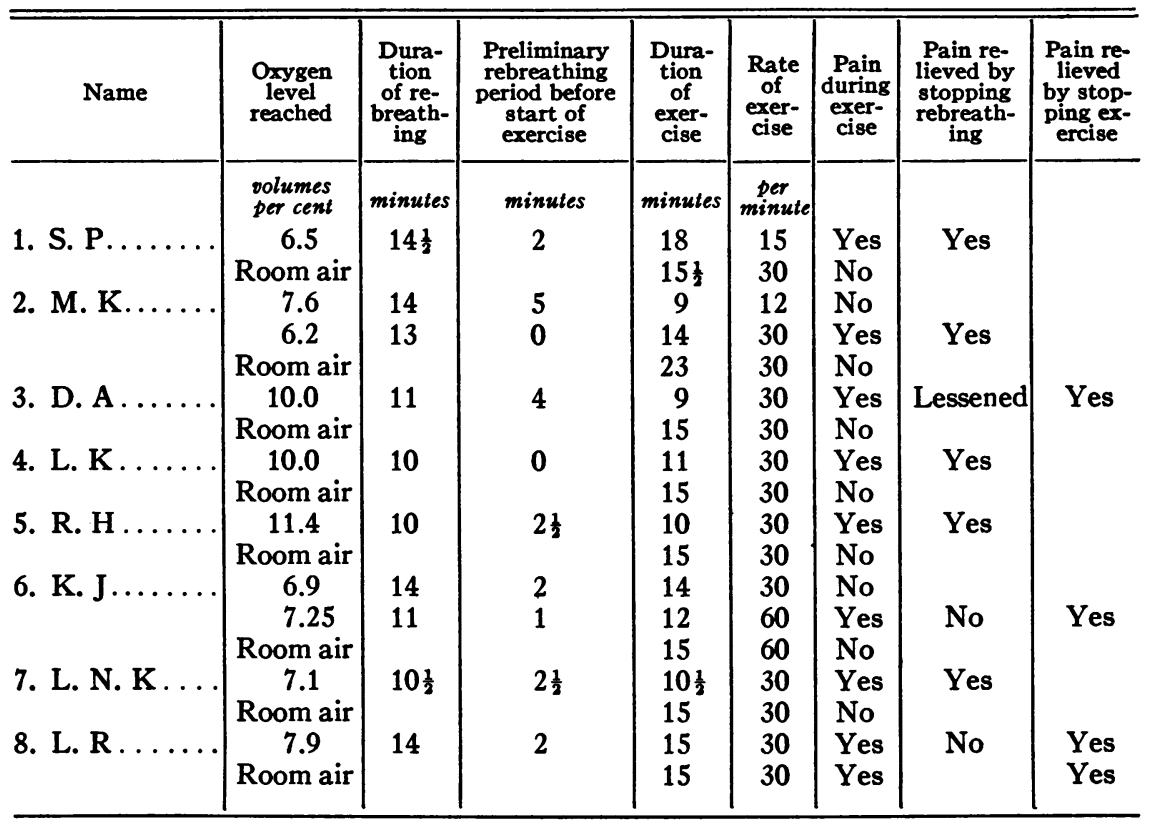

periments. The pain disappeared with the termination of anoxemia in four subjects; in two the pain lessened in intensity, and in the other two it remained unabated. In these last four subjects termination of the exercise led to a disappearance of the pain. In three further experiments, the exercise was stopped after pain had developed for a short time. It was found that the pain diminished slightly and did not disappear until the subject again breathed room air.

The pain in all experiments was usually limited to the muscles of the forearm. Occasionally it was also felt in the flexor muscles of the hand. It began as a mild ache and became progressively more intense but never unbearable. The onset of the pain was gradual but with the termination of anoxemia its offset was sharp. The pain during anoxemia was not as severe as when the circulation was completely occluded in the four subjects in whom this comparison was made.

Seven of the eight subjects did not develop pain during exercise when breathing room air. This indicates that the generalized anoxemia was essential for the appearance of pain in the anoxemia experiments. The eighth subject developed pain during exercise in room air. In his case, some other factor than anoxemia must have been responsible for the appearance of pain. This other factor appears to be the rapidity at which the exercise is performed. 
Other evidence that the rate of exercise is an important factor in the production of pain was observed. For example, K. J. (Number 6, Table I) experienced no pain during anoxemia when the exercise frequency was 30 times per minute, but developed pain when the exercise rate was doubled. Similarly, M. K. (Number 2, Table I) experienced no pain during anoxemia when exercising at the rate of 12 times per minute, but developed pain when the rate was increased to 30 times per minute.

In one subject breathing room air the effect of rate of exercise was studied in greater detail. The subject squeezed the ergograph at rates of $120,80,60,30$ and 15 per minute and the time of onset of mild, moderate and severe pain was noted. The results are recorded in Table II. It will

TABLE II

Time of onset of pain at various rates of exercise

\begin{tabular}{c|c|c|c}
\hline \hline Exercise rate & Mild pain & Moderate pain & Severe pain \\
\cline { 2 - 3 } per minute & seconds & seconds & seconds \\
120 & 60 & 70 & 85 \\
80 & 95 & 115 & 180 \\
60 & 185 & 225 & none \\
30 & none & none & none \\
15 & none & none & none \\
\hline
\end{tabular}

be seen that the time at which pain developed was an inverse function of the rate of exercise. The more rapid the exercise rate, the sooner was the development of pain in the exercising muscles. The pain did not become severe even after five minutes when the rate of contraction was 60 times per minute and no pain appeared within fifteen minutes when the rate was 30 times per minute or slower. A similar result was obtained when the same subject breathed a mixture containing 11.4 volumes per cent of oxygen from a 70 liter Tissot spirometer. Exercise at the rate of 60 times per minute caused pain to develop after three minutes, but when the experiment was repeated with the rate of exercise reduced to 30 per minute no pain developed even after five minutes.

There appears to be an individual variation in the degree of anoxemia required to induce pain during exercise. The oxygen levels of the inspired air at the termination of the anoxemia experiments ranged from 6.2 to 11.4 volumes per cent (Table I).

One subject was studied in greater detail with regard to the effect of varying degrees of generalized anoxemia on the length of time required for the onset of pain. The subject breathed from a Tissot spirometer of 70 liters capacity filled with mixtures of nitrogen and oxygen in varying proportions. The gases were thoroughly mixed by connecting an anaesthesia bag to the outlet pipe of the spirometer and moving the bell up and down 20 times. In each experiment the oxygen content of the inspired air 
was maintained at a fixed level. The subject was kept in ignorance of the proportion of gases in the mixture and the variations in the proportions in the several tests were made non-progressive to obviate psychic influences. Oxygen mixtures ranging from 20.6 to 8.4 volumes per cent were used and the exercise was also repeated with the patient breathing room air and with the arm rendered ischemic by a tourniquet. Exercise was begun one minute after the subject started to breathe from the spirometer. The rate of exercise was kept constant at 60 per minute in all experiments.

The results are shown graphically in Figure 1 . It will be seen that

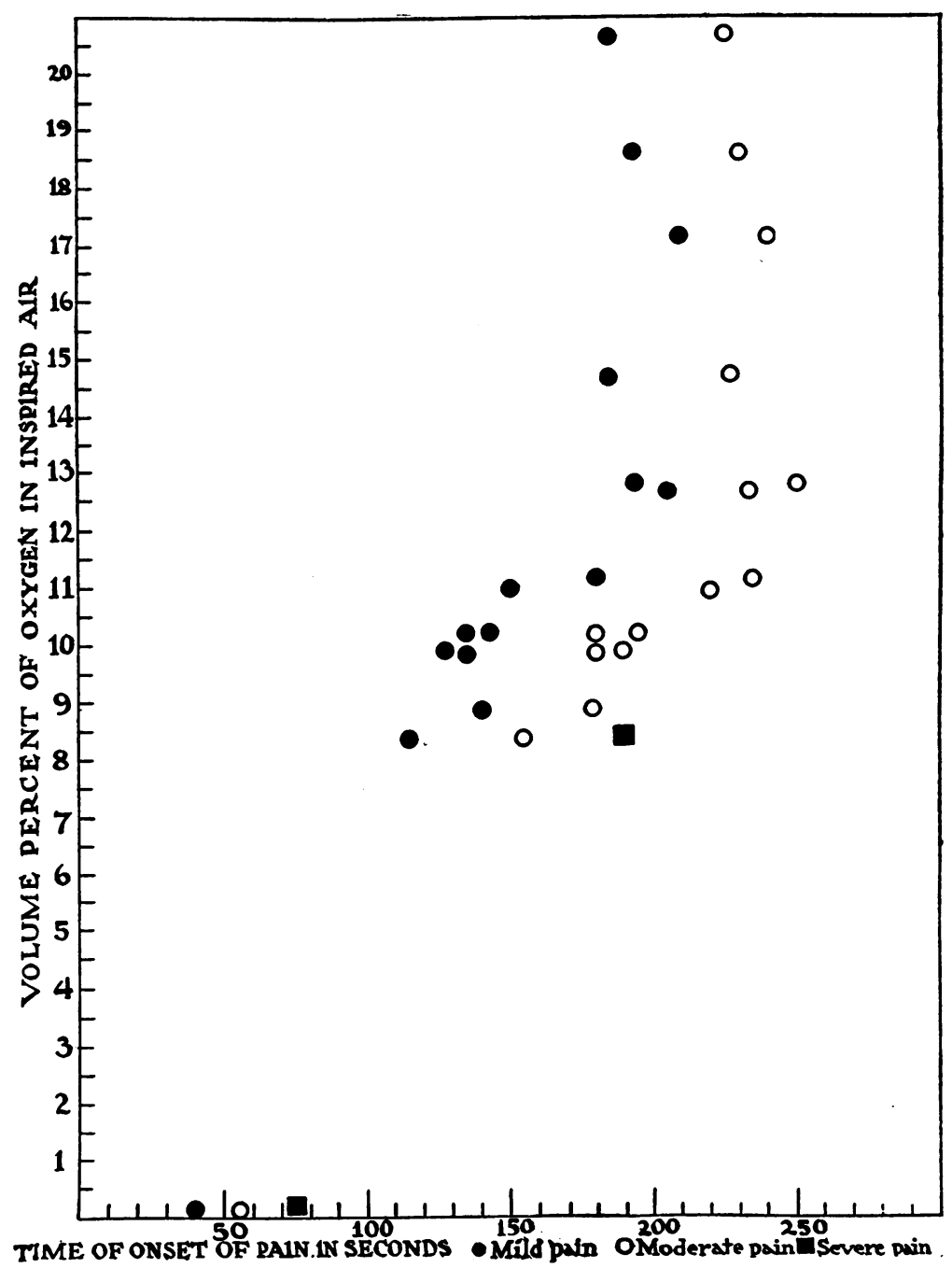

Fig. 1. Time of Onset and Severity of Pain in Relation to the Volume Per Cent of Oxygen in the Inspired Air 
when the oxygen content of the inspired air was between 13 and 20.6 volumes per cent, the time of onset of pain was approximately constant. When the oxygen content was between 8.4 and 13 volumes per cent the time of onset varied, pain occurring earlier in the working muscles as the degree of anoxemia increased. Severe pain was absent until the oxygen level fell to 8.4 volumes per cent. Pain was most severe and came on most rapidly when the arm was rendered completely ischemic while the patient breathed room air.

Several observations on the effect of anoxemia upon the time of onset of pain were made at other exercise frequencies in the same subject. The results, summarized in Table III, agree in showing that pain developed sooner when the exercise was performed during general anoxemia.

TABLE III

Effect of anoxemia on time of onset of pain

\begin{tabular}{c|c|c|c|c}
\hline \hline \multirow{2}{*}{$\begin{array}{c}\text { Exercise } \\
\text { rate }\end{array}$} & $\begin{array}{c}\text { Oxygen content of } \\
\text { inspired air }\end{array}$ & \multicolumn{3}{|c}{ Time of onset of pain } \\
\cline { 2 - 5 } & Mild pain & Moderate pain & Severe pain \\
\hline per minute & volumes per cent & seconds & seconds & seconds \\
80 & 12.1 & 90 & 115 & 130 \\
80 & Room air & 95 & 115 & 180 \\
120 & 11.9 & 35 & 40 & 55 \\
120 & Room air & 60 & 70 & 85 \\
\hline
\end{tabular}

DISCUSSION

The results of these experiments indicate that $(a)$ anoxemia can lead to pain in an exercising skeletal muscle, $(b)$ an individual variation exists in the degree of anoxemia required to produce pain, $(c)$ in a single individual after a sufficiently low oxygen level is reached, the onset and severity of pain vary directly with the degree of anoxemia. The results show further that $(a)$ the rate of exercise is also an important factor in the induction of pain, $(b)$ an individual variation exists in the rate of exercise necessary to initiate pain, $(c)$ in a single individual the onset and severity of pain vary with the rate of exercise.

Anoxemia and rate of exercise, the factors in the production of pain, can be correlated on the following basis: During exercise certain intermediary products of metabolism are formed which are further altered in the presence of a normal oxygen supply. The rate of their formation will be a direct function of the rate of exercise (providing the force of each contraction is kept constant). The rate of exercise may become so rapid that even in the presence of a normal supply of oxygen these metabolic products cannot be oxidized sufficiently rapidly to prevent their concentration in the muscle tissues. If the exercise is continued at this rapid rate 
these metabolic products will reach a concentration above the pain threshold and so pain will be initiated. This condition can be called relative anoxemia.

On the other hand, if the exercise rate be kept constant and the oxygen supply to the muscle be cut down, a stage will be reached in which the oxidation of the metabolic products formed during exercise cannot keep pace with their production. These metabolic products will accumulate, and if the exercise be continued, the threshold for the production of pain will again be exceeded.

Even with a diminished oxygen supply the rate of exercise may be so slow that the oxidative alteration of these products of metabolism can keep pace with their production. No accumulation of these products will ensue and a "steady state" will develop without the appearance of pain.

This theory explaining the foregoing observations is compatible with our present ideas of muscular metabolism. The cause of the pain may be lactic acid which Fletcher and Hopkins (17), Hill (18), Meyerhof (19) and others have shown is formed during exercise; it may be a compound of phosphorus, of creatine, or ammonia, which Eggleton and Eggleton (20), Fiske and Subbarow (21), Embden et al. (22 and 23), Lundsgaard (24 and 25) and others have shown to be formed during exercise; or it may be another product as yet undetermined. In this regard it may be wise to follow the lead of Lewis (1 and 12) and call the pain stimulus the $P$ factor. ${ }^{3}$

These results suggest that while stasis may be a factor in the production of pain in ischemia, anoxemia is essential. The anoxemia may be complete, partial, or relative. The absence of pain during ischemia of the resting extremity, found by Lewis et al. (12) does not necessarily indicate that the metabolic products formed in a resting muscle are qualitatively different from those formed in an exercising muscle. The absence of pain in the resting muscle can perhaps be explained by the fact that its metabolism is a small fraction of that in an exercising muscle (19). The time needed to accumulate sufficient $P$ factor in the ischemic resting muscle to reach the pain threshold would be longer than the interval when pain sensibility is lost in the limb. Lewis, Pickering and Rothschild (26) have shown that the application of a restricting cuff about the arm results in loss of pain sensibility after 40 minutes.

In conclusion, this study suggests that anoxemia is an important factor in the mechanism producing pain in contracting skeletal muscle. Anoxemia may also be an important factor in producing the pain in intermittent claudication and angina pectoris.

${ }^{3}$ The assumption that a chemical product is responsible for the pain may be wrong but the arguments with slight modification will still hold if the pain was due to a physicochemical change. 


\section{SUM MARY}

1. Generalized anoxemia without ischemia can induce pain in an exercising skeletal muscle.

2. Within certain limits the severity and rapidity of onset of the pain varies with the degree of anoxemia and with the rate of exercise of the muscles involved.

3. The pain appears to be due to the accumulation of products of muscular metabolism that require oxygen for their disposal.

I wish to thank Dr. Louis N. Katz for his guidance and criticism and am grateful to the volunteers who kindly acted as subjects of these experiments.

\section{BIBLIOGRAPHY}

1. Lewis, T., Pain in muscular ischemia: its relation to anginal pain. Arch. Int. Med., 1932, 49, 713.

2. Herrick, J. B., The Coronary Artery in Health and Disease. The Harvey Lectures, Williams and Wilkins, Baltimore, 1930-1931, p. 144.

3. Parkinson, J., Coronary thrombosis. Brit. M. J., 1932, 2, 549.

4. Baron, J., The Life of Edward Jenner, M.D., L.L.D., F.R.S., Physician Extraordinary to the King, with Illustrations of His Doctrines and Selections from His Correspondence. Letter to Dr. Heberden during 1778, H. Colburn, London, 1838, p. 39.

5. Parry, C. H., An Inquiry into the Symptoms and Causes of the Syncope Anginosa, Commonly Called Angina Pectoris. Cadell and Davies, London, 1799.

6. Burns, A., Observations on Some of the Most Frequent and Important Diseases of the Heart. Bryce and Co., Edinburgh, 1809, p. 136.

7. Pearcy, J. F., Priest, W. S., and Van Allen, C. M., Pain due to temporary occlusion of the coronary artery in dogs. Am. Heart J., 1929, 4, 390.

8. Sutton, D. C., and King, W. W., Physiological effects of temporary occlusion of the coronary vessels. Proc. Soc. Exper. Biol. and Med., 1928, 25, 842.

9. Sutton, D. C., and Lueth, H. C., Pain: experimental production of pain on excitation of the heart and great vessels. Arch. Int. Med., 1930, 45, 827.

10. Zak, E., Uber den Gefässkrampf bei intermittierendem Hinken und über gewisse kapillomotorische Erscheinungen. Wien. Arch. f. inn. Med., $1921,2,405$.

11. MacWilliam, J. A., and Webster, W. J., Some applications of physiology to medicine: I. Sensory phenomena associated with defective blood supply to working muscles. Brit. M. J., 1923, 1, 51.

12. Lewis, T., Pickering, G. W., and Rothschild, P., Observations upon muscular pain in intermittent claudication. Heart, 1931, 15, 359.

13. Reid, C., Experimental ischemia : sensory phenomena, fibrillary twitchings, and effects on pulse, respiration, and blood-pressure. Quart. J. Exper. Physiol., 1931, 21, 243.

14. Keefer, C. S., and Resnik, W. H., Angina pectoris: a syndrome caused by anoxemia of the myocardium. Arch. Int. Med., 1928, 41, 769. 
15. Rothschild, M. A., and Kissin, M., Anginal syndrome induced by gradual general anoxemia. Proc. Soc. Exper. Biol. and Med., 1932, 29, 577.

Rothschild, M. A., and Kissin, M., Production of the anginal syndrome by induced general anoxemia. Am. Heart J., 1933, 8, 729.

Rothschild, M. A., and Kissin, M., Induced general anoxemia causing S-T deviation in the electrocardiogram. Am. Heart J., 1933, 8, 745.

16. Dietrich, S., and Schwiegk, H., Das Schmerzproblem der Angina Pectoris. Klin. Wchnschr., 1933, 12, 135.

17. Fletcher, W. M., and Hopkins, F. G., Lactic acid in amphibian muscle. J. Physiol., 1907, 35, 247.

18. Hill, A. V., Muscular Movement in Man. McGraw-Hill Co., New York, 1927.

19. Meyerhof, O., Die Chemischen Vorgänge im Muskel. J. Springer, Berlin, 1930.

20. Eggleton, P., and Eggleton, G. P., The inorganic phosphate and a labile form of organic phosphate in the gastrocnemius of the frog. Biochem. J., 1927, 21, 190.

21. Fiske, C. H., and Subbarow, Y., The nature of the "inorganic phosphate" in voluntary muscle. Science, 1927, 65, 401.

22. Embden, G., Grafe, E., and Schmitz, E., Utber Steigerung der Leistungsfähigkeit durch Phosphatzufuhr. Ztschr. f. physiol. Chem., 1921, 113, 67.

23. Embden, G., and Zimmermann, Margarete, Úber die Bedeutung der Adenylsäure für die Muskelfunktion: I. Das Vorkommen von Adenylsäure in der Skelettmuskulatur. Ztschr. f. physiol. Chem., 1927, 167, 137.

24. Lundsgaard, E., Untersuchungen über Muskelkontraktionen ohne Milchsäurebildung. Biochem. Ztschr., 1930, 217, 162.

25. Lundsgaard, E., Uber die Energetik der anaeroben Muskelkontraktion. Biochem. Ztschr., 1931, 233, 322.

26. Lewis, T., Pickering, G. W., and Rothschild, P., Centripetal paralysis arising out of arrested bloodflow to the limb, including notes on a form of tingling. Heart, 1931, 16, 1. 